\title{
Integrated geophysical investigations for seismic zoning in a coastal area of Northern Sicily $\left(^{*}\right)$
}

\author{
P. Cosentino ** - V. Rizzo ** \\ Received on December 5th, 1982
}

\section{Abstract}

The area, about $225 \mathrm{~km}^{2}$ large, ranging from the Eleuterio river to the $\mathrm{S}$. Leonardo river on the northern coast of Sicily, has suffered many earthquakes in the past centuries and has for many years recognized as a seismic area. This paper presents a set of integrated geophysical studies carried out in that area, including: i) a statistical study of the past earthquakes in order to define the earthquake risk (PGV or PGA risk), ii) a set of laboratory density measurements carried out on samples of rocks ( 82 samples), iii) a shallow refraction investigation ( 290 profiles) in order to study the mechanical properties of such rocks, iv) a deep geoelectrical investigation (200 VES) in order to reconstruct the main geological features with particular regard to the geometrical distribution of the elastic and plastic formations which have been piled up during the complex overthrusting of the Sicilian chain, and $v$ ) a detailed study of the possible amplifications of the groundmotions due to the geometry and the mechanical characteristics of the shallow and intermediate rocks. The results, combined wih the knowledge of the regional tectonic features and the locations of the involved seismogenetic volumes, allow the formation of a picture of the seismic responses and the connected seismic risk.

* Paper partially read at the 42th E.A.E.G. Meeting, Istanbul, 1980. Work carried out in the frame of the * Progetto Finalizzato di Geodinamica» of the Italian C.N.R., publ. No. 518.

** Istituto di Geofisica Mineraria, University of Palermo, Via M. Stabile, 110 90139 Palermo (ITALY). 


\section{Riassunto}

L'area indagata (ampia circa $225 \mathrm{~km}^{2}$ ), che si estende tra i fiumi Eleuterio e S. Leonardo sulla costa settentrionale della Sicilia è caratterizzata da una notevole sismicità storica che ne impone l'attenzione dal punto di vista della valutazione del rischio sismico. Questo lavoro presenta uno studio geofisico integrato che comprende: $i$ ) uno studio statistico dei terremoti storici per la definizione del rischio di terremoto « a priori " (espresso come PGV o PGA), ii) una serie di misure di densità in laboratorio su campioni di roccia ( 82 campioni), iii) una indagine sismica a rifrazione superficiale ( 290 profili) per studiare le proprietà meccaniche delle rocce nei primi $15-20 \mathrm{~m}$ di spessore, $t v$ ) un'indagine geoelettrica profonda (200 SEV) per ricostruire le caratteristiche geotettoniche con particolare riguardo alla distribuzione geometrica delle formazioni plastiche ed elastiche che sono state sovrapposte durante il complesso sovrascorrimento della catena siciliana e v) uno studio dettagliato delle possibili amplificazioni dovute alla geometria ed alle caratteristiche meccaniche delle rocce superficiali e profonde. I risultati di tali indagini, considerati alla luce delle conoscenze tettoniche e geologiche regionali e delle ubicazioni dei volumi sismogenetici coinvolti, permettono di ottenere un quadro delle risposte sismiche e del rischio sismico dell'area indagata.

\section{1. - InTRODUCTION}

This paper presents a set of geophysical prospecting surveys carried out in order to define and evaluate the seismic risk in a northern coastal area of Sicily which has been seismologically active in the past centuries.

The evaluation of seismic risk has been tackled by means of different methodologies requiring large financial and operative efforts, in order to prepare a set of data which can ben suitably arranged to obtain the point estimates. As a matter of fact, the thorough evaluation of seismic risk is not a simple and definite problem, and in this light it is necessary to have a set of available data including seismological, geotectonic, geological and soil mechanical pieces of information. Thus the evaluation of seismic risk in a definite spot can be made by an accurate semi-quantitative integration of all the available data, which individually can only furnish a partial and not meaningful evaluation.

The methodologies used in the present work include: i) a statistical study of the past earthquakes, ii) a geologic and geolithological survey, iii) a shallow refraction seismic survey, iv) 
a set of laboratory density measurements, and $v$ ) a geoelectrical resistivity survey which has been restricted to a smaller representative area due to lack of the necessary large financial supports.

\section{2. - Seismological outlines of Western Sicily}

The seismological history of Sicily has been thoroughly studied in a set of previous papers (e.g., Cosentino and Ficarra, 1974; idem, 1975; Cosentino and Enescu, 1976; Cosentino and Luzio, 1977) and further studies have been focalized on the seismicity of Western Sicily (e.g., Cosentino, 1978 a).

The map of epicenters of the past earthquakes in Western Sicily is presented in fig. 1. The estimates of the basic seismological parameters have been obtained using the results of Cosentino (1978 a) corrected for conservative purposes.

With reference to the cited paper, the following exponential and truncated exponential relations have been used:

EXP. $\quad N(M)=\alpha \exp \left\{-\beta\left(M-M_{\alpha}\right)\right\} \quad$ for $M \geqslant M_{\mathrm{o}}$,

and

TR. EXP.

$$
N(M)=\alpha \frac{1-\exp \left\{\beta\left(M_{p}-M\right)\right\}}{1-\exp \left\{\beta\left(M_{p}-M_{\alpha}\right)\right\}} \quad \text { for } M_{\circ} \leqslant M<M_{p}
$$

$$
N(M)=0 \quad \text { for } M \geqslant M_{p}
$$

where $N(M)$ is the cumulative annual frequency, $M_{0}$ is the threshold magnitude value and $M_{p}$ is maximum possible magnitude in the considered region.

In fig. 2 the experimental data are shown, and the best conservative fit of relations [1] and [2] is presented. The values of $\alpha, \beta$ and $M_{p}$ are selected following Cosentino (1978 a) and corrected using conservative $\triangle \operatorname{tmv}$ confidence intervals for $L . S$. estimates of $\beta$ and conservative mean error for the unbiased M.L. estimate of $M_{p}$. The resulting values of the parameters are also shown in fig. 2 . 


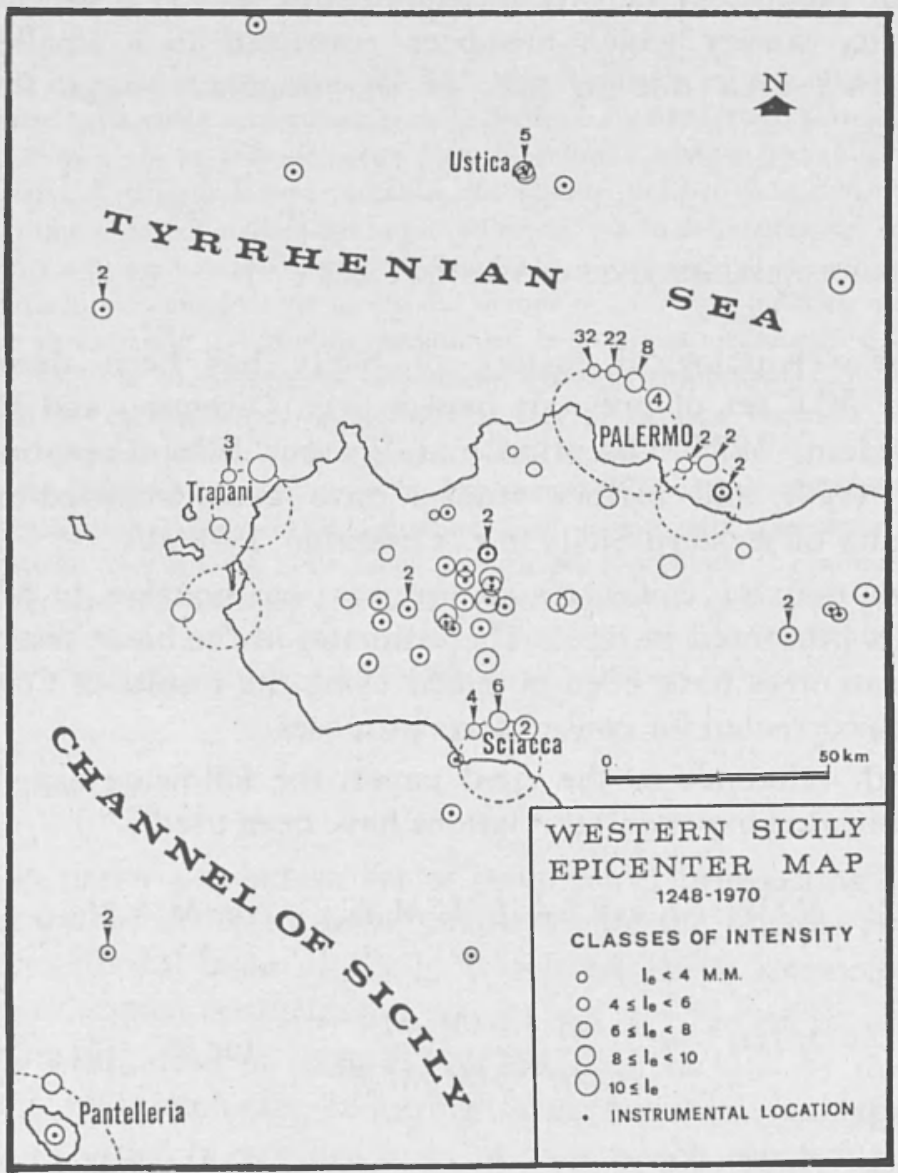

Fig. 1 - Map of epicenters in Western Sicily from 1248 up to 1970. Most of the earthquakes have been located on the bases of the historical data. In doubtful cases a dashed line surrounds the area of probable location. The numbers labeling some earthquakes correspond to different epicentrically coincident events.

It should be noticed that the mean hypocenter depth for Sicilian earthquakes is about $10-30 \mathrm{~km}$ (normal earthquakes) but in the northern coastal area many intermediate earthquakes of the Southern Tyrrhenian sea (depths ranging from 90 to $150 \mathrm{~km}$ ) are generally felt. 


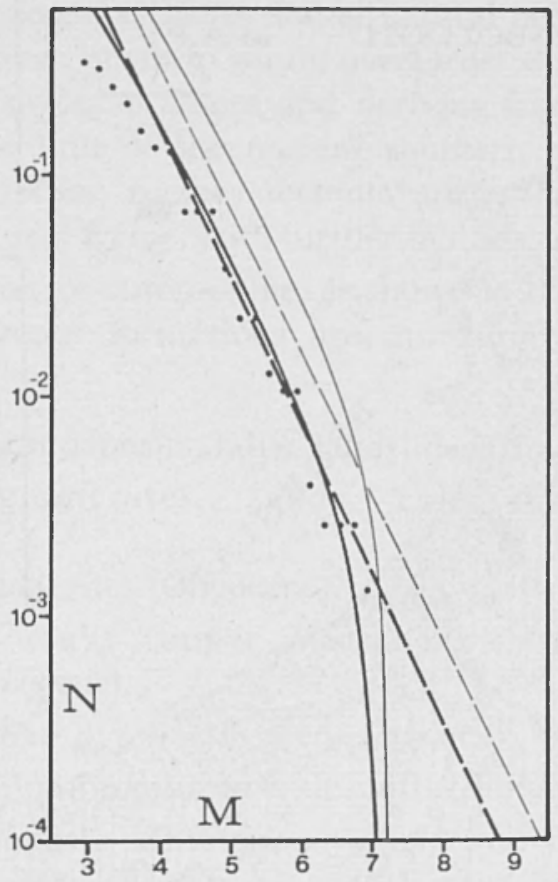

Fig. 2 - Cumulative annual frequencies of the earthquakes in Western Sicily. The best fits (thick lines) of the exponential (dashed line) and truncated exponential (full line) models are presented. The conservative fits are respectively represented by the thin lines. The values of the parameters corresponding to the conservative fit are $\alpha=68.74, \beta=1.27$ and $M_{p}=7.24$

\section{3. - Geological outLines}

The investigated area - presented in fig. $3-$ is a portion of the northern Sicilian coastal area and it is morphologically characterized by two large ridges with summits more than 1.000 $\mathrm{m}$ high, a wide peripheral hilly area and a flat coastal plane with some jutting stiff bodies.

From a structural point of view the geologic formations are part of a stratigraphic-structural unit of the Mesozoic-Paleogenic 


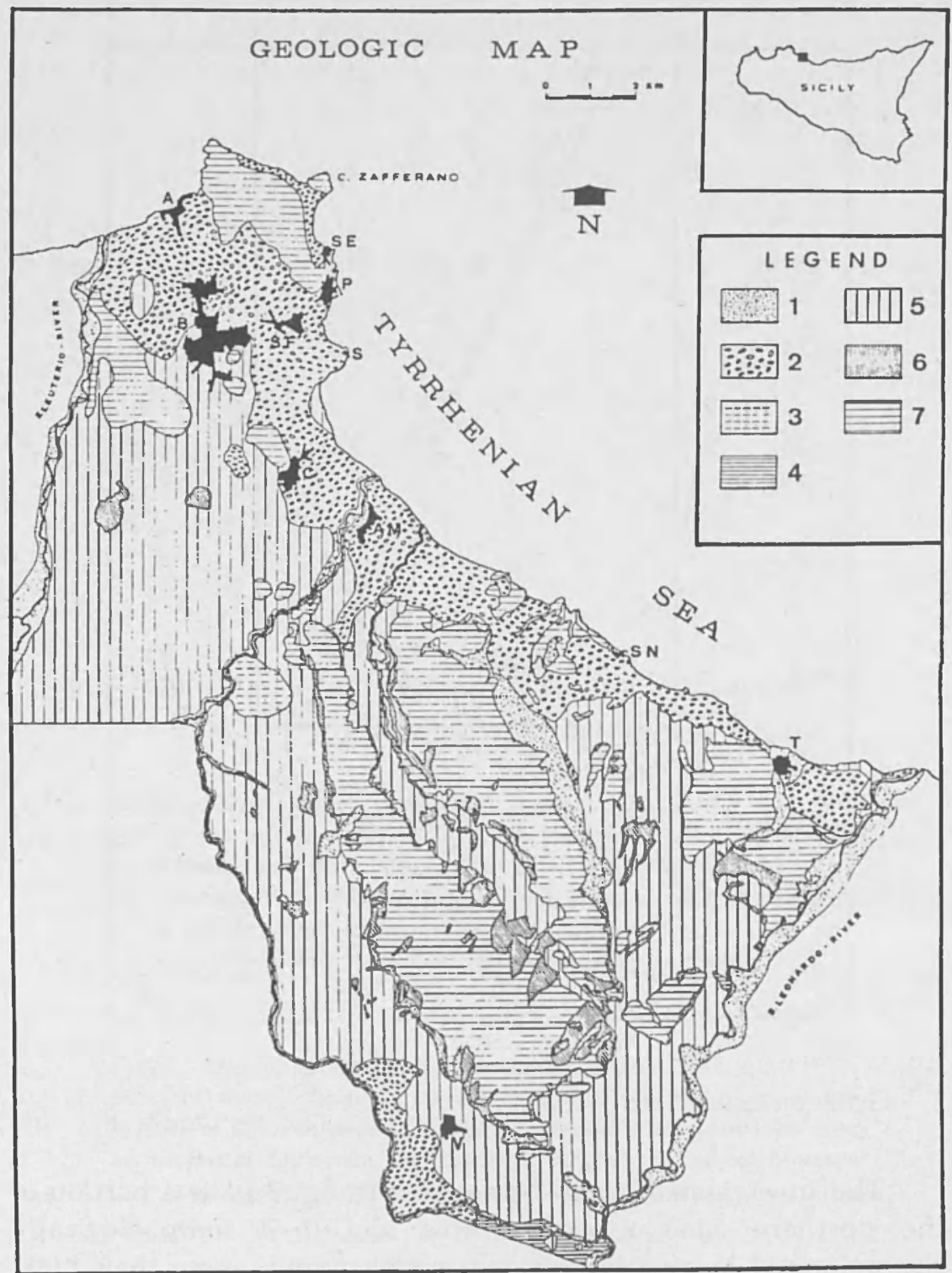

Fig. 3 - Geologic map of the investigated area. The meanings of the numbers in legend are shown in the text. Capital letters indicate villages, namely $A=A s p r a, B=B a g h e r i a, S E=S$. Elia, $\mathrm{P}=$ Porticello, $\mathrm{SF}=\mathrm{S}$. Flavia, $\mathrm{C}=$ Casteldaccia, $\mathrm{AM}=$ Altavilla Milicia, $\mathbf{S N}=\mathrm{S}$. Nicola, $\mathrm{T}=$ Trabia and $\mathrm{V}=$ Ventimiglia di Sicilia. 
period, homogeneous as facies and structural behaviour, geometrically piled up from north to south, overthrusted southward during the Langhian-Tortonian stages and deriving from the "Imerese" paleogeographic unit of the ancient southern margin of Thetys. After upper Pliocene further tectonic stages have modified the miocenic structural frame, with further faulting and dislocations.

The geometry of outcroppings is shown in the geologic map in fig. 3. The various formations are numbered and respectively correspond to:

1) Alluvium deposits, talus, landslides (Holocene),

2) Conglomerates, sands, calcarenites (OligocenePleistocene),

3) Quartzarenites (Oligocene),

4) Blue clays (upper Miocene), "argille variegate" (Cretaceous-Paleocene),

5) Numidian flysch (Oligocene-Miocene),

6) Orbitolina limestones with marls (Albian-Cenomanian),

7) Organogenic limestones, radiolarites, cherty limestones, pinky dolomites (Mesozoic).

Initially, in order to carry out an " a priori " zoning of the territory, the various formations have been roughly grouped in three classes (following Faccioli, 1977) according to their mechanical behaviour:

1) Rock sites. Includes competent rock sites only, with $S$ wave velocities of order of $1,000 \mathrm{~m} / \mathrm{s}$ or higher and not more than 2-3 m of soil or weathered materials on sound rock. It includes the previous 6) and 7) formations.

2) Stiff soil sites. Identifies sites on stiff clay, dense sand and gravel, as well as conglomerates and partially weathered sedimentary rocks, having velocities higher than about $250 \mathrm{~m} / \mathrm{s}$ close to surface, whereas depth to rock may typically range between 5 and a few tens of meters. It includes the previous 2), 3), 4 ), and 5) formations.

3) Alluvium sites. These are underlain by deposits of alluvial soils of intermediate stiffnes, with $S$ wave velocities between about 100 and $250 \mathrm{~m} / \mathrm{s}$. Depth to bedrock can range between a few tens 
and several hundreds of meters. It corresponds to the previous 1) formation.

By means of the above mentioned basic parameters of the frequency-magnitude truncated exponential relation and the site parameters given by Faccioli (1977), the Peak Ground Velocity (PGV) risk (Cosentino, 1978 b) has been obtained for focal distances of 20 and $100 \mathrm{~km}$ (approximately corrisponding to normal and intermediate depths), with reference to velocities of 3,10 and $20 \mathrm{~cm} / \mathrm{s}$ (approximately corresponding to VI, VIII, and IX MSK macroseismic intensities). The values have been calculated for 20 and 100 year periods and site classes 1,2 and 3. The results are presented in table 1 and the sites distribution is shown in the map of " a priori " zoning (fig. 4).

\section{4. - SEISMIC RIGIDITY METHOD}

A more detailed approach to the seismic microzoning can be carried out using the seismic rigidity method, which has been

TABLE 1

Peak Ground Velocity (PGV) for 20 and $100 \mathrm{~km}$ focal distances in various site classes. $R_{x}(Y)$ is the risk of occurrence during $X$ years of at least one earthquake giving $Y$ PGV. The calculated values of the maximum possible PGV for each sites are also reported.

\begin{tabular}{|cccccccc|}
\hline $\begin{array}{c}\text { site } \\
\text { class }\end{array}$ & $\begin{array}{c}\text { PGVmax } \\
\mathrm{cm} / \mathrm{s}\end{array}$ & $R_{20}(3)$ & $R_{20}(10)$ & $R_{20}(20)$ & $R_{100}(3)$ & $R_{100}(10)$ & $R_{100}(20)$ \\
\hline \multicolumn{7}{c|}{ Focal distance $=20 \mathrm{Km}$} \\
\hline 1 & 28.75 & 1.00 & 0.49 & 0.09 & 1.00 & 0.97 & 0.39 \\
2 & 33.18 & 1.00 & 0.65 & 0.16 & 1.00 & 0.99 & 0.58 \\
3 & 24.85 & 1.00 & 0.92 & 0.10 & 1.00 & 1.00 & 0.42 \\
\hline \multicolumn{7}{c}{ Focal distance $=100 \mathrm{Km}$} \\
\hline 1 & 6.67 & 0.31 & 0.00 & 0.00 & 0.85 & 0.00 & 0.00 \\
\hline 3 & 11.89 & 0.78 & 0.03 & 0.00 & 1.00 & 0.13 & 0.00 \\
12.75 & 1.00 & 0.13 & 0.00 & 1.00 & 0.49 & 0.00 \\
\hline
\end{tabular}




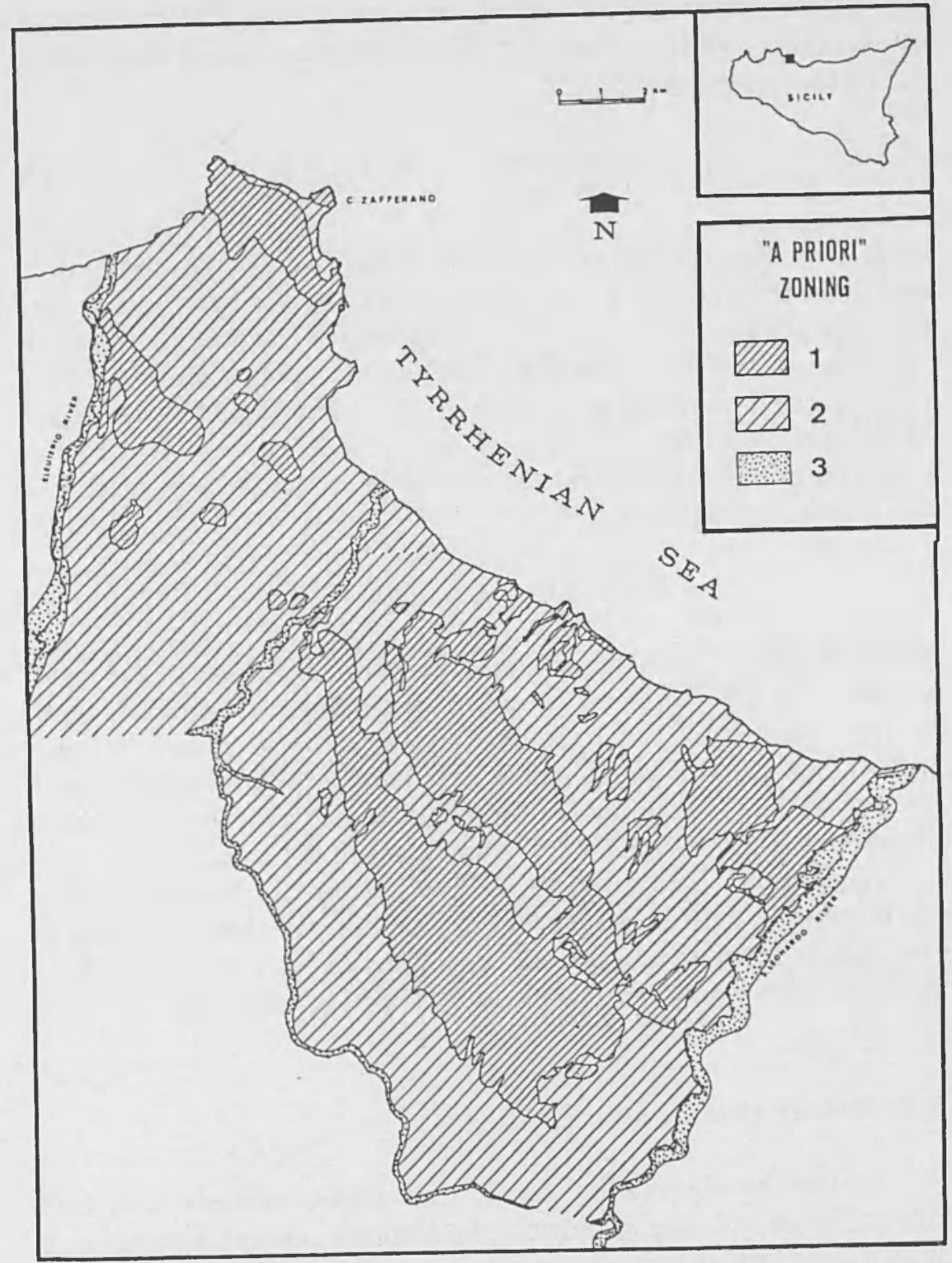

Fig. 4 - Map of the site distribution for the a a priori » zoning (following Faccioli, 1977). The numbers correspond to different site classes explained in the text. 
proposed by Medvedev (1965). It consists in the measurements of the seismic rigidity in various spots of the considered area, using the following expression:

$$
R=\overline{V \delta}=\left(\sum_{i=1}^{n} V_{i} \delta, h_{i}\right) / \sum_{i=1}^{n} h_{i}
$$

where $n$ is the number of the various layers underlying the spot, $h_{i}$ are their thicknesses, $V_{t}$ are velocities of the $P$ waves and $\delta_{i}$ are the densities of the rocks constituting the layers. In order to calculate the seismic response of the various spots, the study of the rigidity can be limited to a depth of $10 \mathrm{~m}$. The expected increment of the macroseismic intensity $\Delta I$ with respect to a reference point $\mathbf{r}$ during an earthquake can be evaluated in a spot $\mathbf{q}$ by means of the following relation:

$$
\Delta I=1.67 \log \left(R_{\mathrm{r}} / R_{\mathrm{q}}\right)+\exp \left(-0.04 z^{2}\right)
$$

where $R_{\mathrm{r}}$ and $R_{\mathrm{q}}$ respectively are the seismic rigidities of the $\mathbf{r}$ and q spots and $z$ is the depth in meters of the eventual phreatic level. In the investigated area the phreatic level in all places is lower than $12 \mathrm{~m}$, so that the contribution of the second term in relation [4] is practically negligible. As the reference spot it is useful to choose the highest rigidity point surveyed in the area.

In order to calculate the rigidity values 290 Seismic Profiles (S. P.) and 82 density measurements (D. M.) have been executed in the whole area, except in the mountainous belt extending from NNW to SSE where the logistic accessibility is hard (fig. 5).

\subsection{Density measurements (D.M.)}

As can be observed in fig. 5, the various samples have been drawn from all the geological formations, except formation 4 , which is at best marginal and very restricted.

The measurements of the densities of the samples have been grouped in order to calculate the mean density of the formations, as well as to obtain the variation coefficients. 


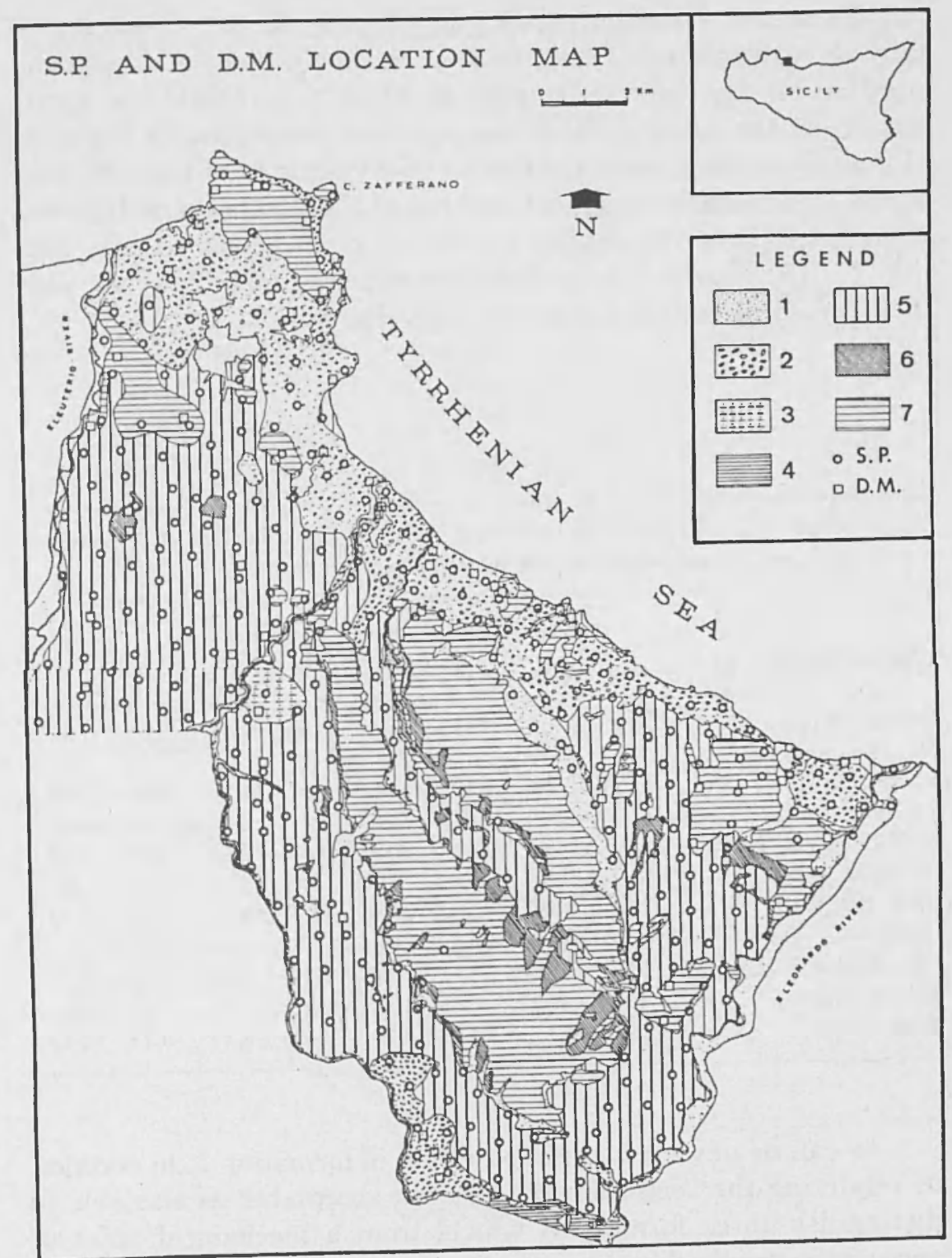

Fig. 5 - Map of location of seismic profiles (S.P.) and density measurements (D.M.) in the investigated area. The numbers correspond to the different geologic formations which are mentioned in the text. 
Since the variation coefficient referring to the samples pertaining to formation 2 has resulted relatively high, a subsequent subdivision has been attempted in order to evaluate the mean density of the calcarenites in the northern plane close to Bagheria village (2a), sands and calcarenites of Ventimiglia village (2b) and sands, conglomerates and calcarenites of the coastal band between Altavilla Milicia village and the mouth of S. Leonardo river (2c) (fig. 6). The results obtained are presented in table 2, as are also included some results concerning the velocities.

TABLE 2

Mean values and coefficients of variations of densities, velocities of $P$ waves of overburden and consolidated layer for the various formations.

\begin{tabular}{lcccccccc} 
FORMATIONS & 1 & $2 \mathrm{a}$ & $2 \mathrm{~b}$ & $2 \mathrm{c}$ & 3 & 5 & 6 & 7 \\
\hline DENSITY $\left(\mathrm{g} / \mathrm{cm}^{3}\right)$ & 2.71 & 2.13 & 1.86 & 2.01 & 2.49 & 2.10 & 2.66 & 2.75 \\
No. of samples & 3 & 10 & 8 & 4 & 3 & 12 & 3 & 20 \\
VAR. COEFF. & 0.13 & 0.09 & 0.19 & 0.01 & 0.09 & 0.15 & 0.01 & 0.06 \\
\hline OVERB. VEL. (km/s) & 0.56 & 0.67 & 0.62 & 0.43 & 0.60 & 0.53 & 0.45 & 0.69 \\
No. of samples & 16 & 25 & 39 & 7 & 3 & 171 & 3 & 26 \\
VAR. COEFF. & 0.24 & 0.30 & 0.30 & 0.06 & 0.04 & 0.27 & 0.31 & 0.32 \\
\hline CONS. L. VEL. (km/s) & 2.08 & 2.37 & 2.15 & 2.19 & 2.04 & 2.07 & 2.22 & 2.57 \\
No. of samples & 16 & 25 & 39 & 7 & 3 & 171 & 3 & 26 \\
VAR. COEFF. & 0.19 & 0.33 & 0.18 & 0.10 & 0.06 & 0.19 & 0.25 & 0.19 \\
\hline
\end{tabular}

As can be observed, the subdivision of formation 2 , in addition to rendering the coefficient of variation acceptable, is also able to distinguish three formations which, from a mechanical point of view, are actually different.

In addition to the measurements carried out on the lithologically defined samples, a set of 19 samples of cultivated soil have been measured, giving an average density of $1.601 \mathrm{~g} / \mathrm{cm}^{3}$. 


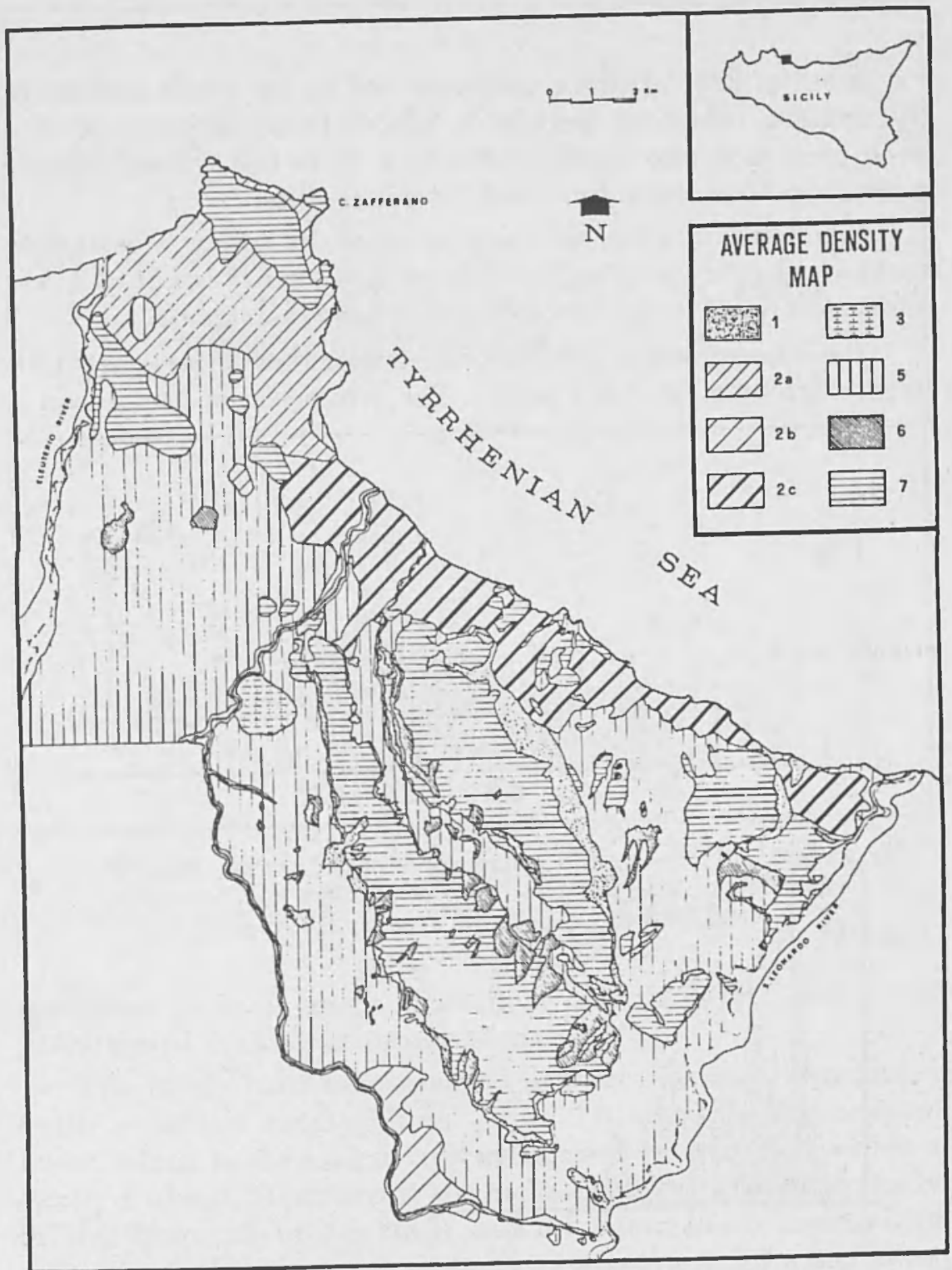

Fig. 6 - Map showing the distribution of the outcropping formations characterized by different average densities. The values of the densities are presented in Table 2 . 


\subsection{Seismic profiles (S.P.)}

A set of 290 S.P. have been executed in the whole area using the shallow refraction method. A BISON 1570/c seismograph has been used with two fixed geophones, a 70 m line with 24 impact points providing both direct and inverse profiles.

The interpretation has been executed by means of standard techniques using non-horizontal layered patterns, except in a few cases, where particular structures have been individuated.

The true velocities and the mean thicknesses of the layers have been calculated for every profile. The interpretation has shown a

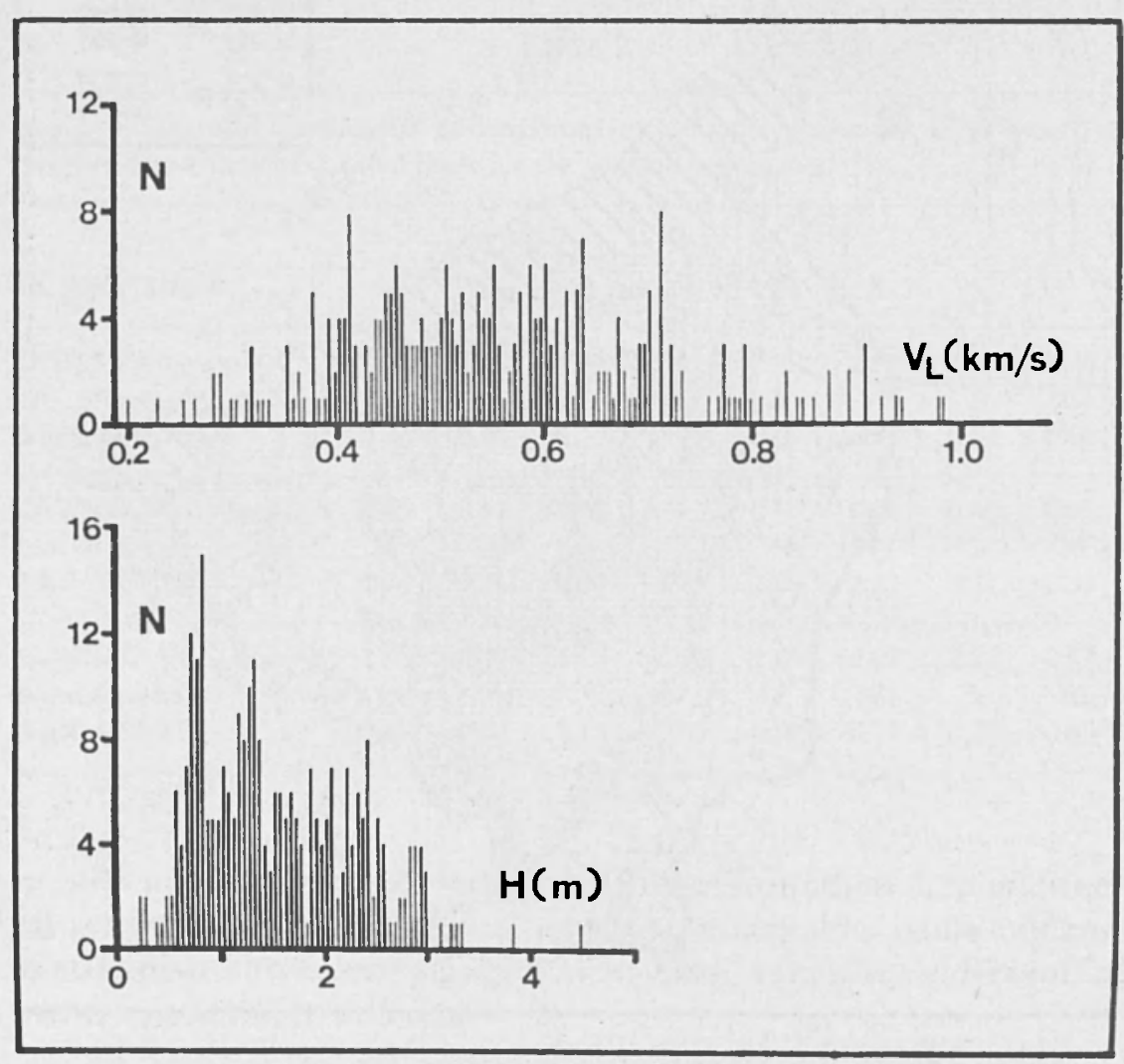

Fig. 7a - Histograms representing the frequencies of the obtained values of velocities (above) and thicknesses (below) of the overburden in the whole investigated area. 


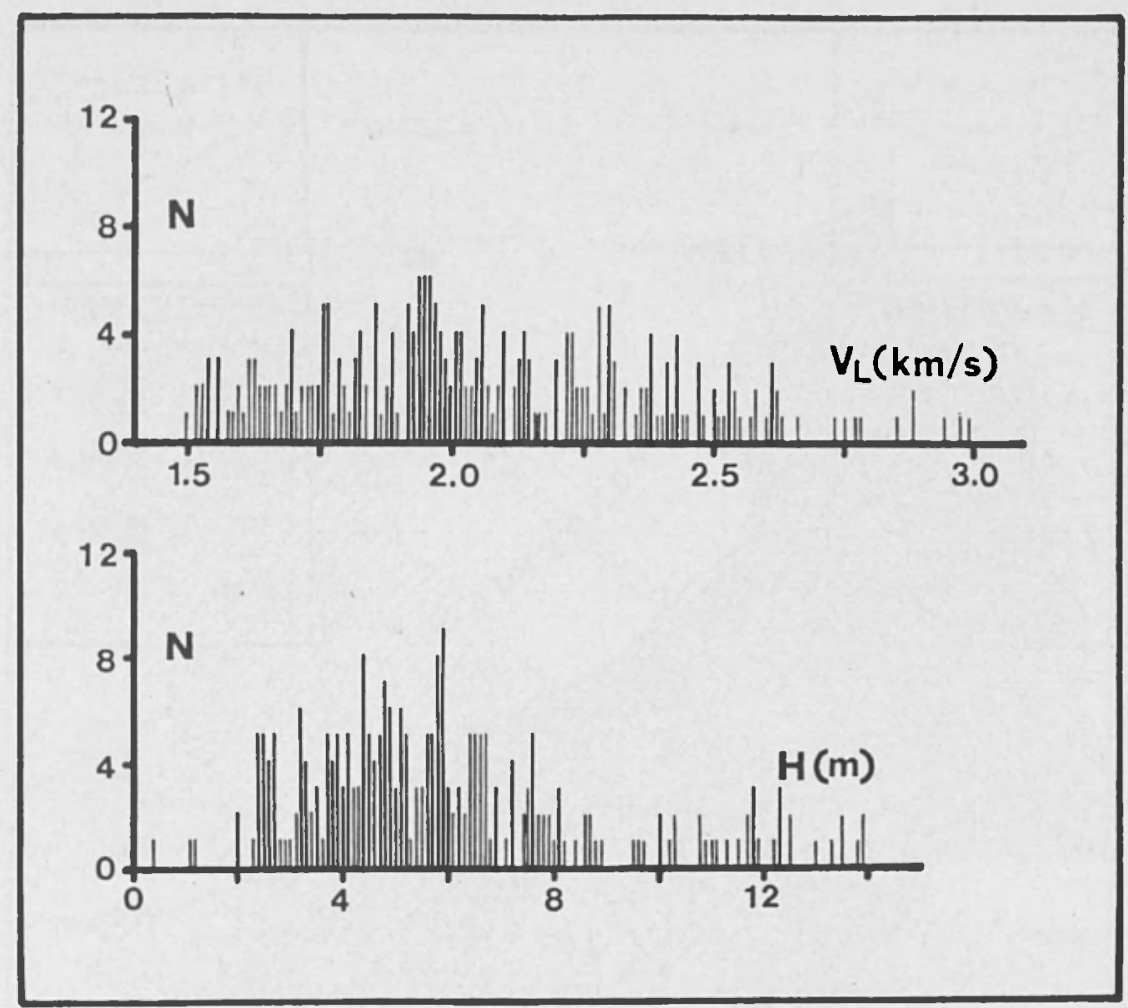

Fig. $7 \mathrm{~b}$ - Histograms representing the frequencies of the obtained values of velocities (above) of the consolidated layer and dephts (below) of its top in the whole investigated area.

minimum of two and a maximum of four layers within the investigated thicknesses (about $20 \mathrm{~m}$ ).

The layers have been grouped in three classes: $i)$ overburden (with velocities ranging from 0.2 to $1.0 \mathrm{~km} / \mathrm{s}$ ), ii) consolidated layer, which is the lowest layer recognized in every S.P. within a depth of about $20 \mathrm{~m}$, having the highest value of velocity (tipically falling from 1.5 to $3.0 \mathrm{~km} / \mathrm{s}$ ) and iii) intermediate layers, with velocities higher than that of the overlaying overburden and lower than that of the underlaying consolidated layer.

Four histograms are shown in figs. $7 \mathrm{a}$ and $7 \mathrm{~b}$, respectively representing the frequencies of velocities and thicknesses of the 


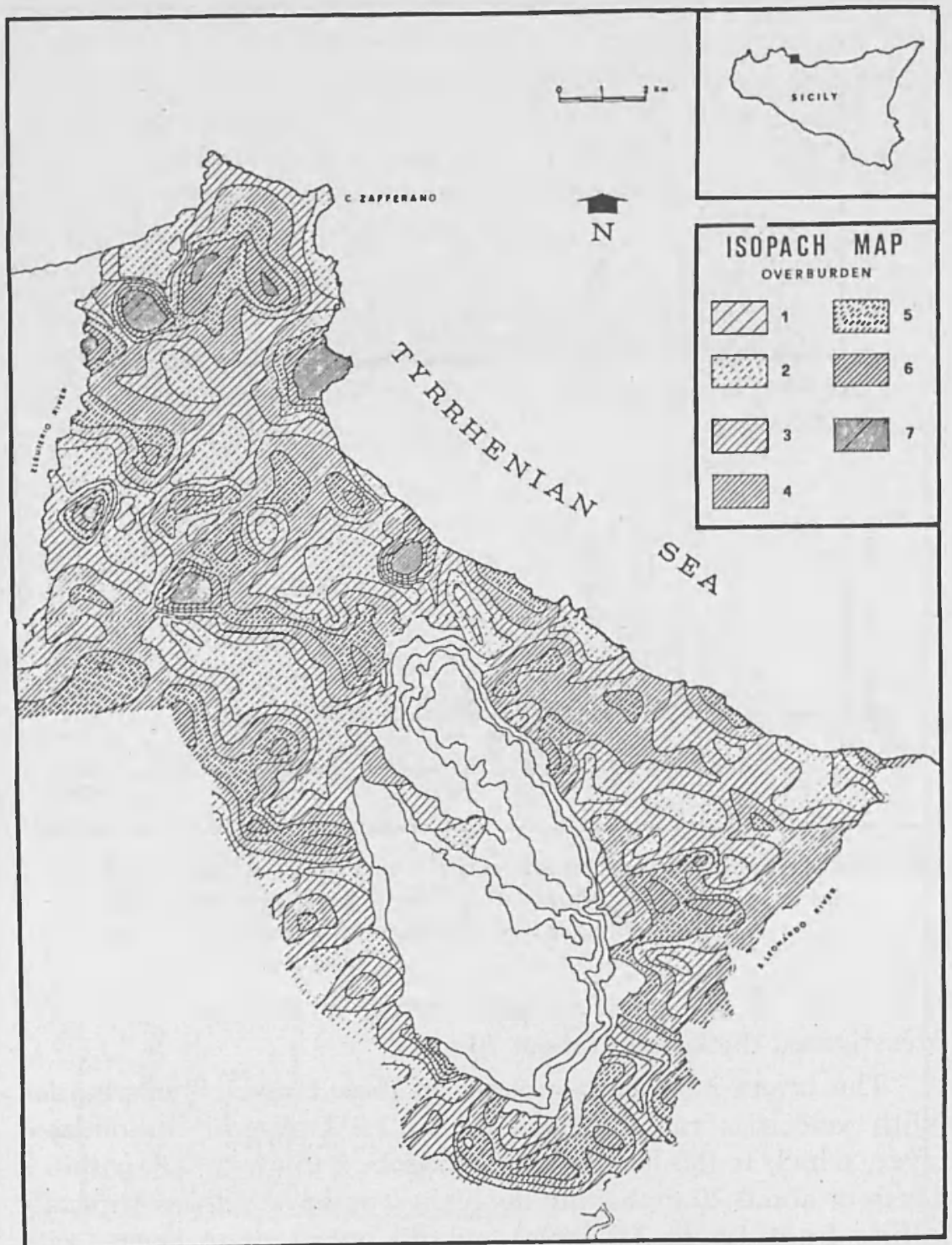

Fig. 8 - Map of the thicknesses of the overburden in the investigated area. The labeled thicknesses range from less than $1 \mathrm{~m}$ (1) to more than $6 \mathrm{~m} \mathrm{(7),} \mathrm{the} \mathrm{increasing} \mathrm{intermediate} \mathrm{step} \mathrm{being} \mathrm{as} \mathrm{high}$ as $1 \mathrm{~m}$. 


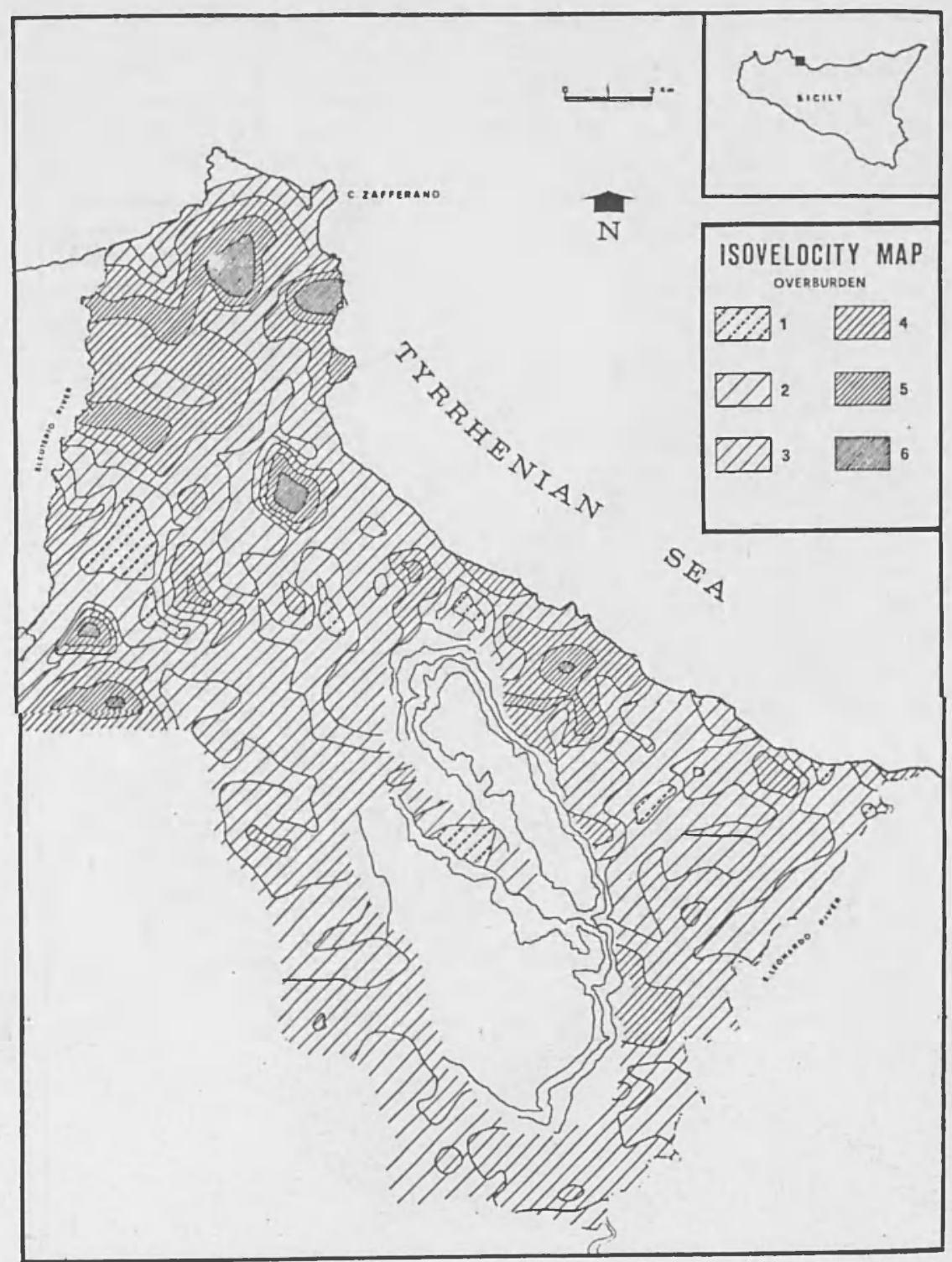

Fig. 9 - Map the velocities of the overburden in the whole investigated area. The labeled velocities range from less than 0.35 $\mathrm{km} / \mathrm{s}$ (1) to more than $0.95 \mathrm{~km} / \mathrm{s}(6)$, the increasing intermediate step being as high as $0.15 \mathrm{~km} / \mathrm{s}$. 


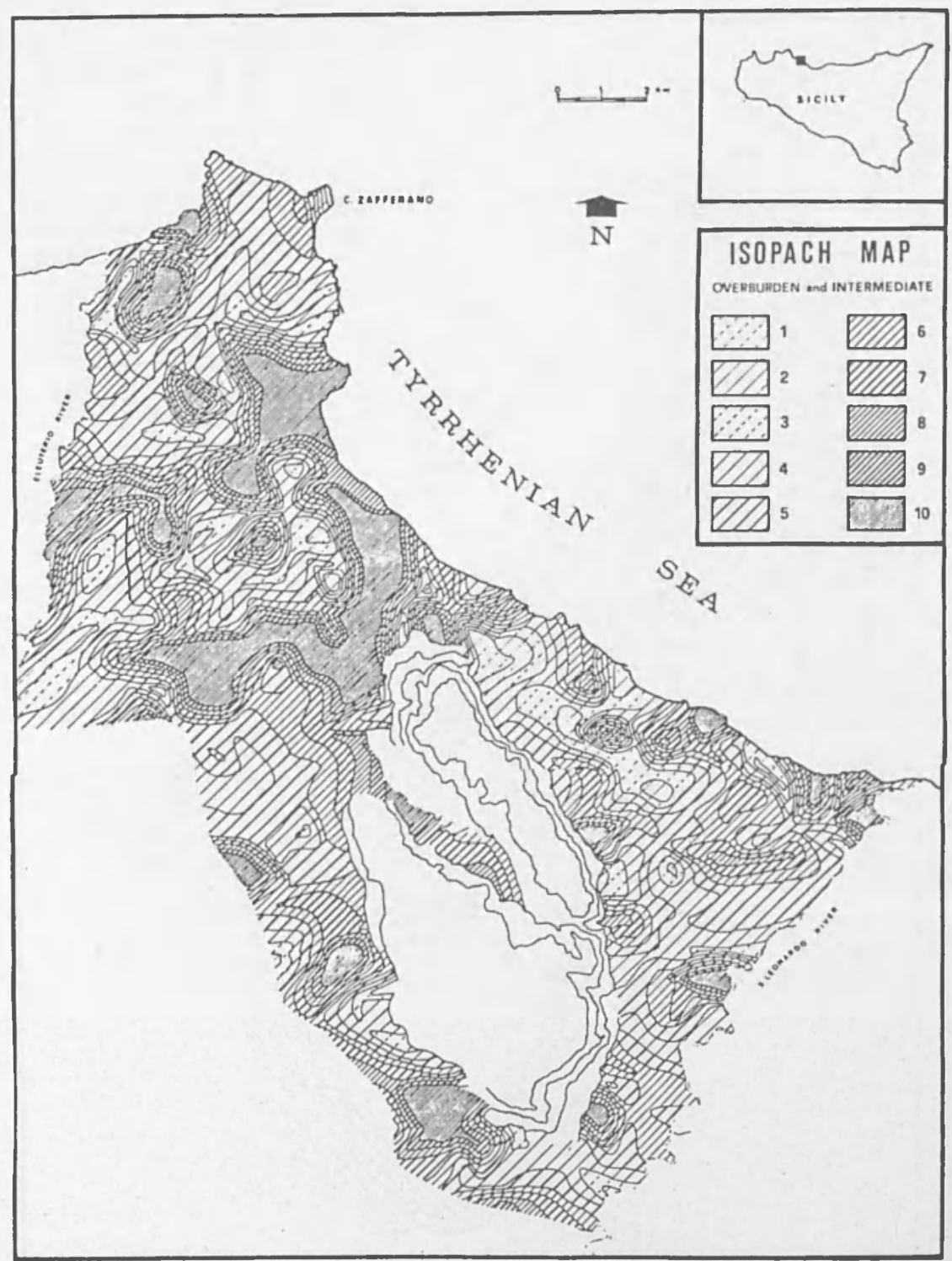

Fig. 10 - Map of the depths of the top of the consolidated layer in the whole investigated area. The labeled dephts range from less than $2 \mathrm{~m}$ (1) to more than $10 \mathrm{~m} \mathrm{(10),} \mathrm{the} \mathrm{increasing} \mathrm{intermediate}$ step being as high as $1 \mathrm{~m}$. 


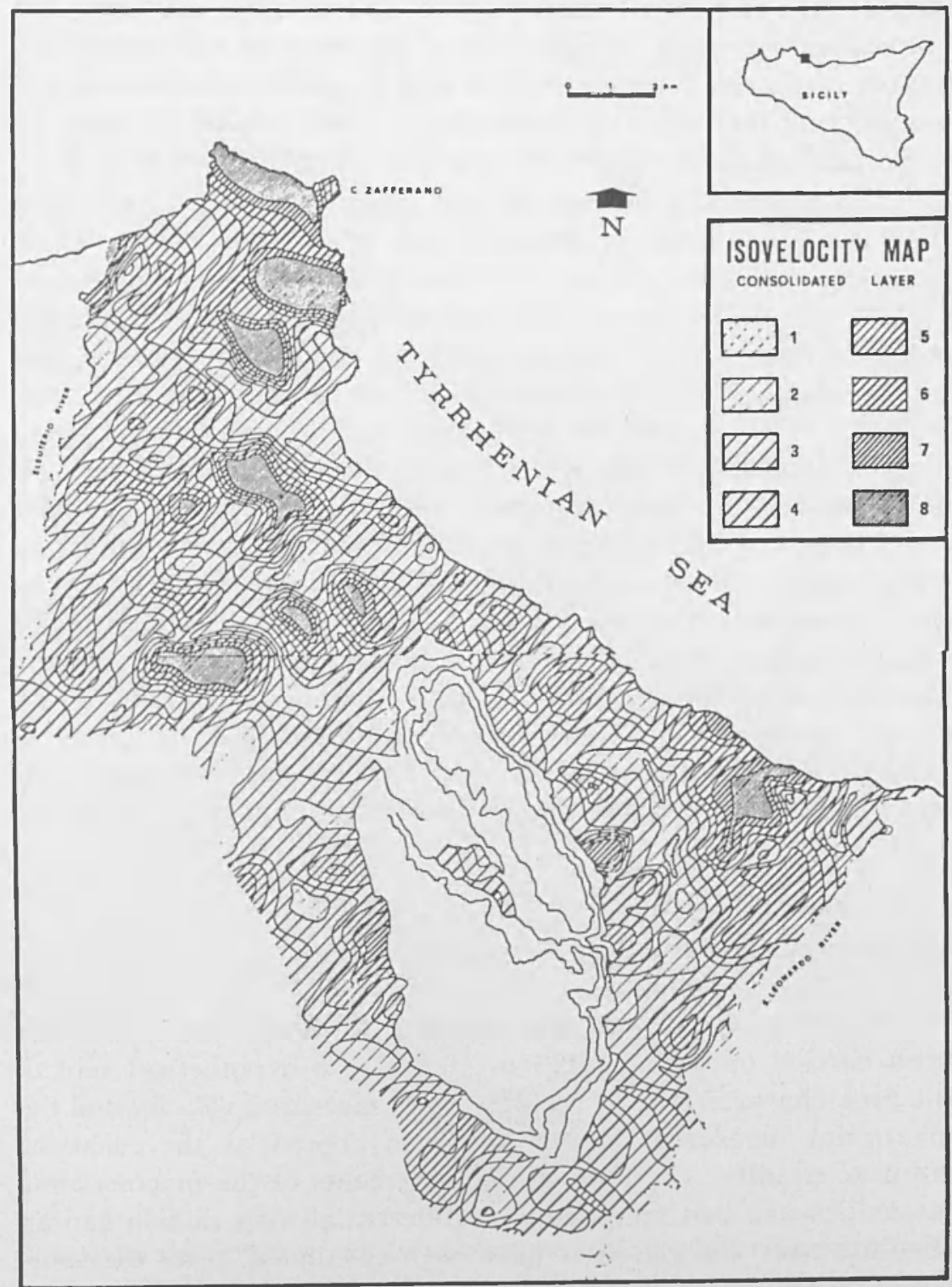

Fig. 11 - Map of the velocities of the consolidated layer in the whole investigated area. The labeled velocities range from less than $1.6 \mathrm{~km} / \mathrm{s}$ (1) to more than $2.8 \mathrm{~km} / \mathrm{s}$, the increasing intermediate step being as high as $0.2 \mathrm{~km} / \mathrm{s}$. 
overburden and those connected with the consolidated layer. The corresponding space distributions of the previous parameters are shown respectively in figs. $8,9,10$ and 11 , while the coefficients of variation of the velocities of overburden and consolidated layer for every geological formations are calculated and included in table 2.

The analysis of histograms and maps allows the observation that the overburden is characterized by velocity values which generally fall from 0.4 to $0.75 \mathrm{~km} / \mathrm{s}$, with highest values and highest variability in the north-western part of the area, while the south-eastern part is characterized by more homogeneous and intermediate values; the thicknesses of overburden generally range from 1.0 to $5.0 \mathrm{~m}$, with frequent lateral variations along the whole map and mostly in the western part. The consolidated layer is characterized by very scattered values of velocities, generally ranging from 1.5 to $2.7 \mathrm{~km} / \mathrm{s}$, as well as by large lateral variations with highest values in the north-western part of the map and in the area surrounding the village of Trabia. The scattering of the velocity values is likely due to the lateral variations of both the lithology and the cementation degree. The depths of the consolidated layers are generally between 3.0 and $8.0 \mathrm{~m}$, areas of maximum depth being in the western part, south of Capo Zafferano; lateral variations also in dephts are frequent in the whole area.

\subsection{Macroseismic intensity increments}

The estimate of the macroseismic intensity increments has been carried out using relation [4], where a hypothetical spot of the area characterized by the maximum measured velocity and the maximum measured density has been chosen as the reference point of rigidity. The map of the increments of the macroseismic intensities can ben regarded as a differential map rather than an absolute one. The rigidities have been calculated in all the spots based on only $10 \mathrm{~m}$ of earth.

The reference rigidity $R_{\mathrm{q}}$ has been chosen as:

$$
R_{\mathrm{q}}=4,560 \mathrm{~m} / \mathrm{s} \cdot 3.059 \text { tons } / \mathrm{m}^{3}=13,950 \text { tons } /\left(\mathrm{m}^{2} \mathrm{~s}\right) .
$$




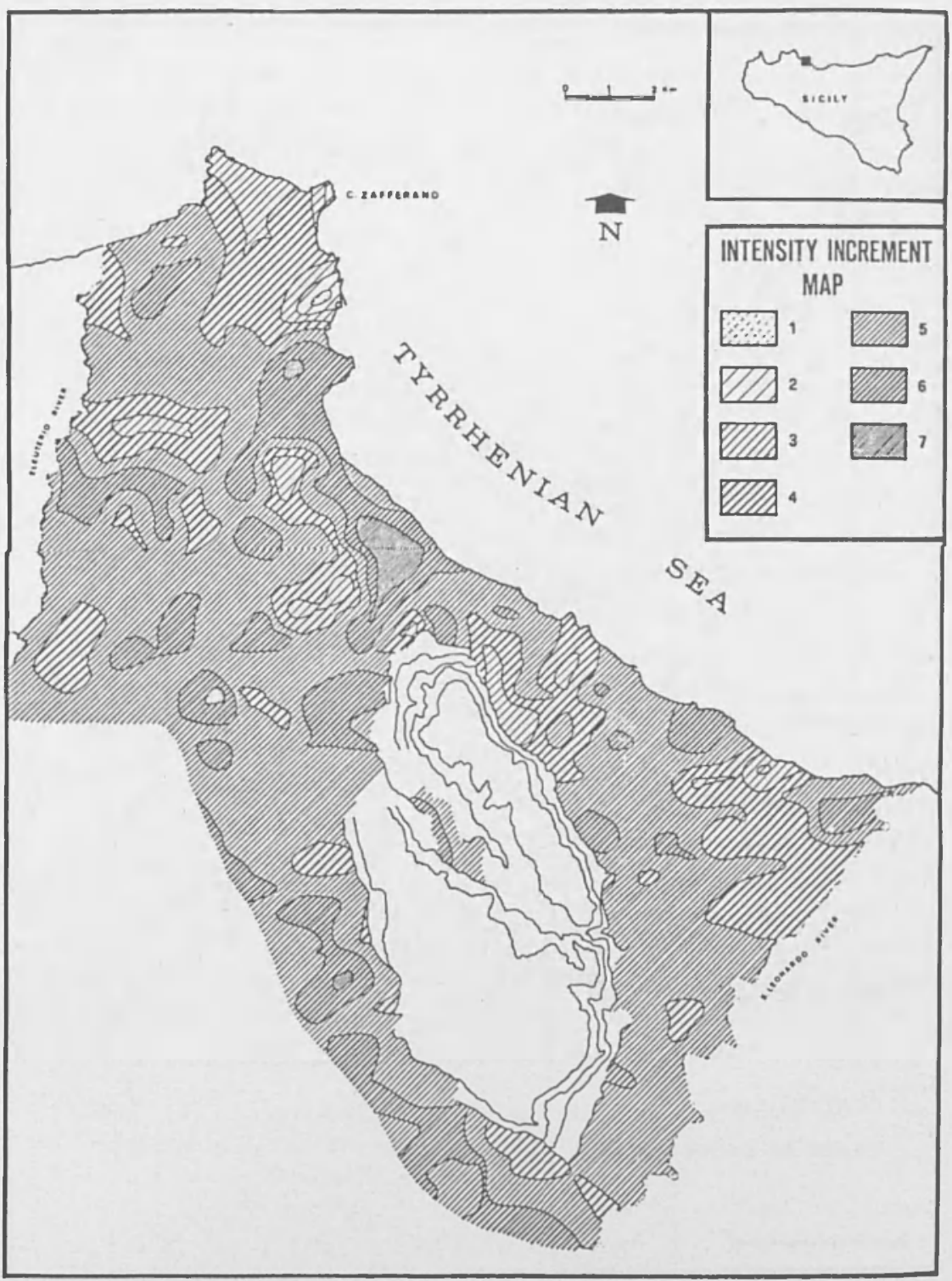

Fig. 12 - Map of the increments of macroseismic intensities in the whole investigated area. The values should be regarded rather as relative increments. The labeled increments range from less than 1 degree (1) to more than 3.5 degrees (7), the increasing intermediate step being as high as 0.5 intensity degrees. 


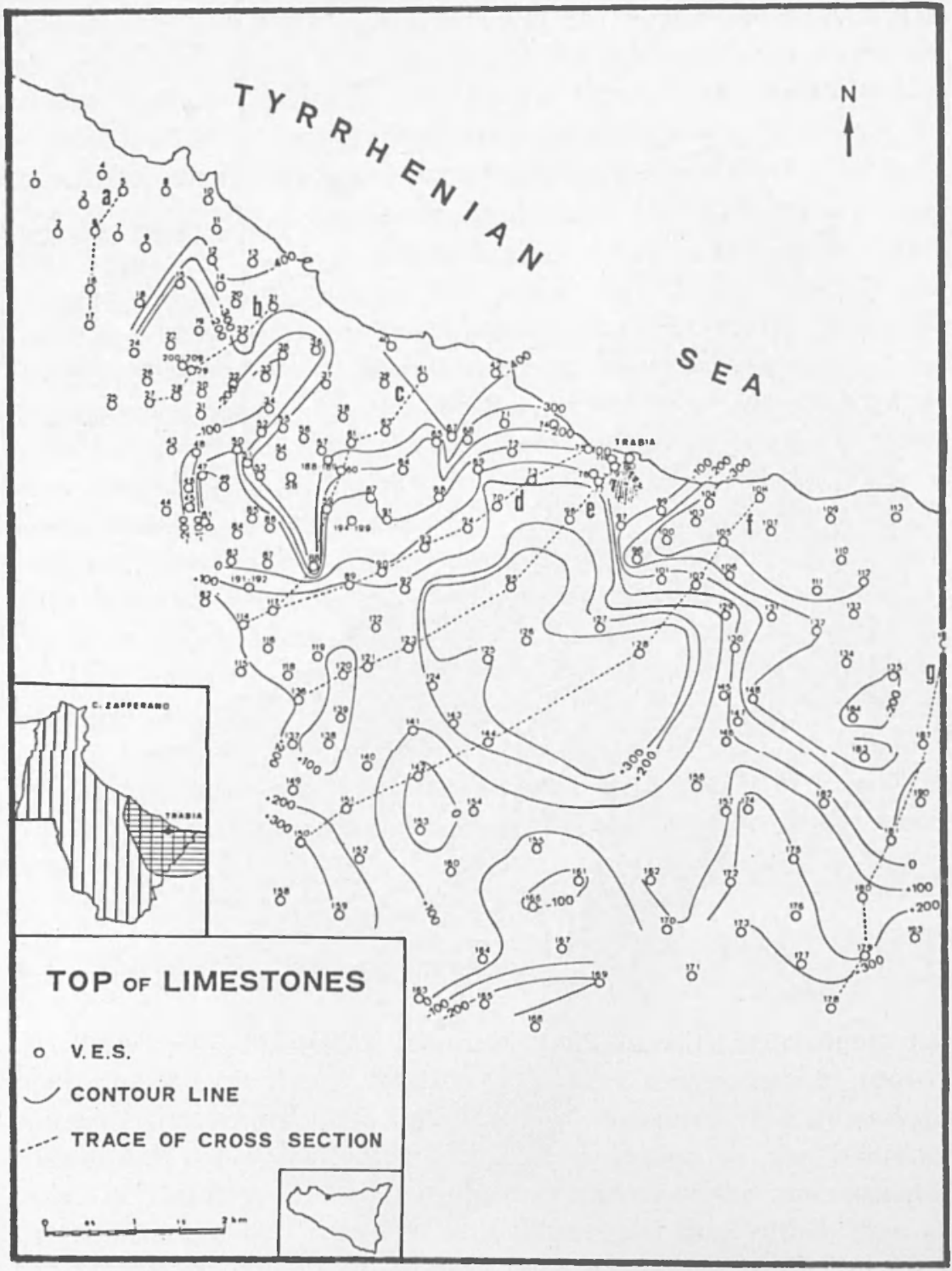

Fig. 13 - Map of the area surroundings the village of Trabia, where an extensive geoelectrical survey has been carried out. The overlap with the whole investigated area is shown in the small square. The locations of 200 deep V.E.S., the traces of the cross sections presented in figg 14 and 15 , as well as the contour lines of the top of limestones buried under the Numidian Flysch are presented. 


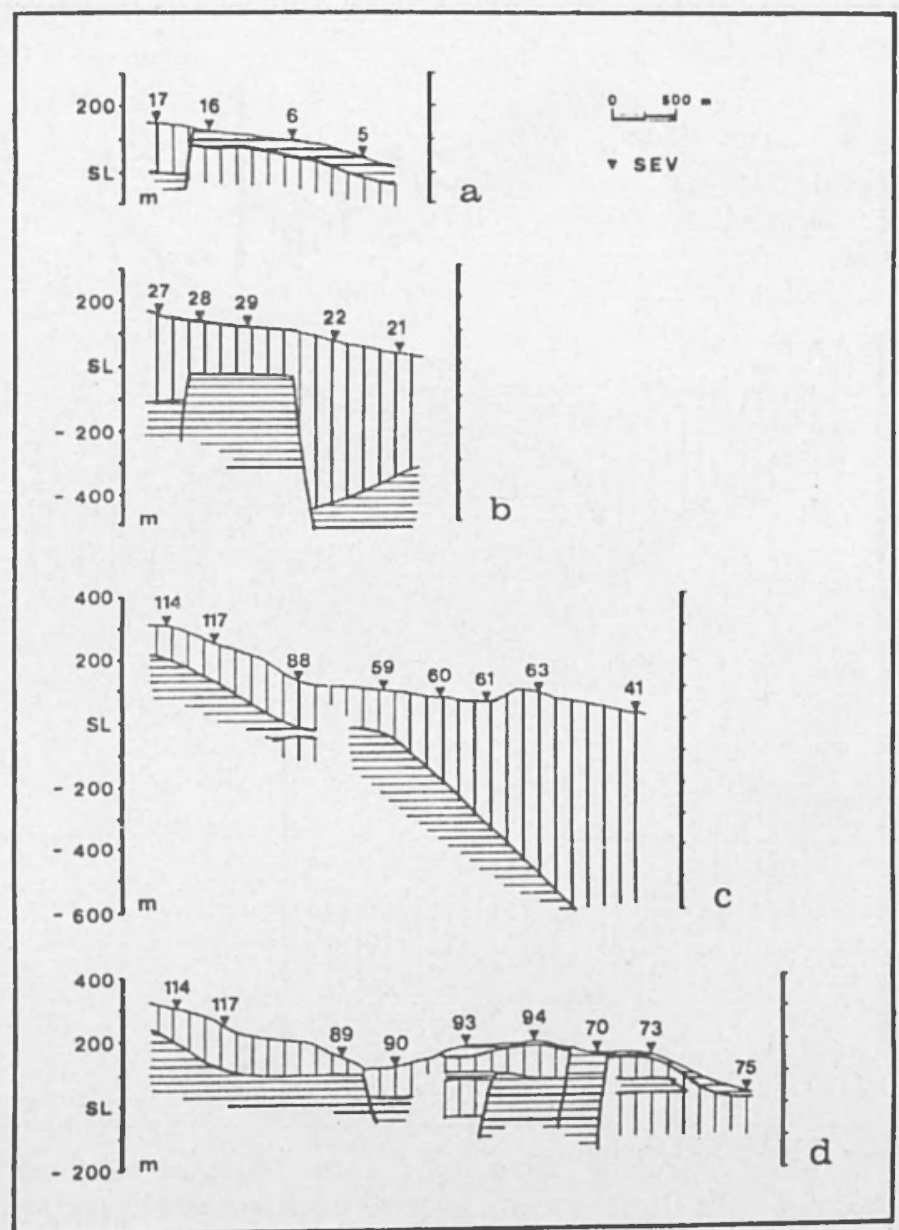

Fig. 14 - Interpreted cross sections, the traces of which are mapped in fig. 13. The plastic (vertical lines) and elastic (horizontal lines) formations are distinguished.

The obtained map is presented in fig. 12. It can be noticed that highest seismic risk is present in the coastal area between the villages of Solanto and Altavilla Milicia, in the southern band NW-SE elongated including Ventimiglia village, while restricted high risk zones are dispersed in the whole map. The lowest risk 

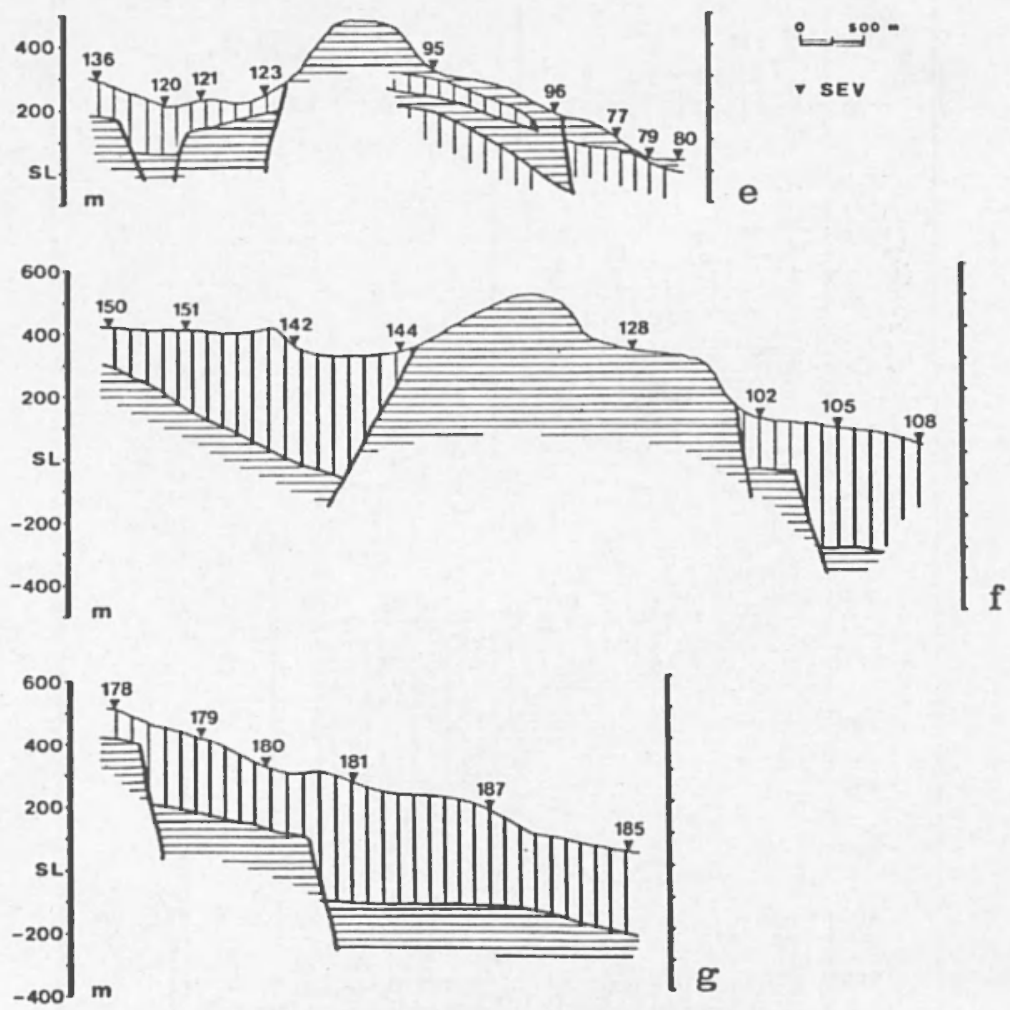

Fig. 15 - Interpreted cross sections, the traces of which are mapped in fig. 13. The plastic (vertical lines) and elastic (horizontal lines) formations are distinguished.

zones correspond to Porticello village, Capo Zafferano and a small area west of Trabia village.

\section{RESONANCE EFFECTS}

The macroseismic intensity map gives no account of the possible differentiations of seismic risk due to particular resonance 


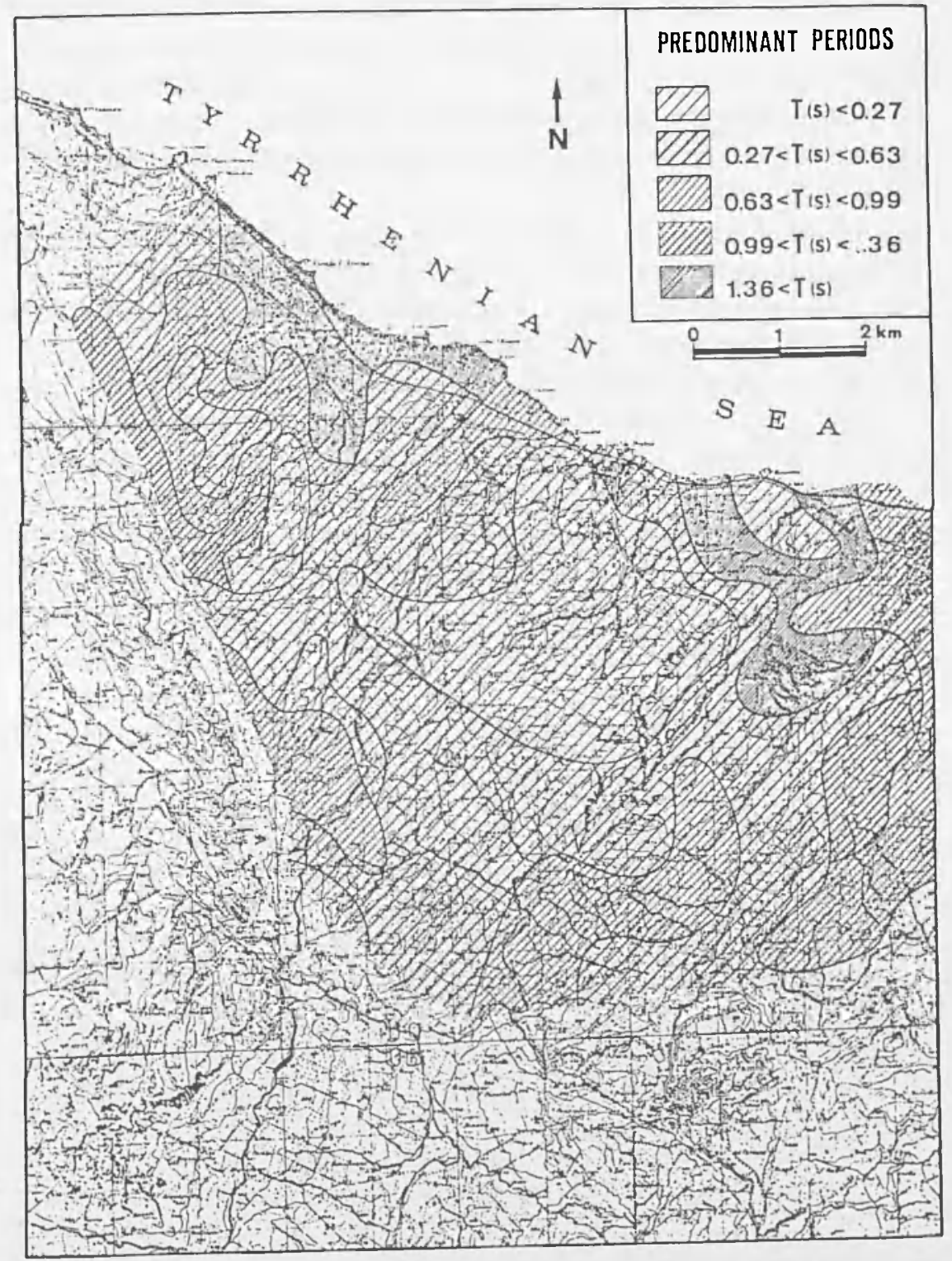

Fig. 16 - Map of the distribution of the predominant resonance periods in the area which has been investigated by geoelectrical survey. 
phenomena, which can occur when the mechanical properties of the layers give rise to amplifications of particular frequencies. In order to evaluate these possible phenomena, a geoelectrical survey has been executed. The area which has been selected for this purpose is shown in fig. 13. It is about $56 \mathrm{~km}^{2}$ and it surrounds the coastal village of Trabia.

In this area a set of 200 deep V.E.S. using Schlumberger array with $A B \max =1,000 \mathrm{~m}$ have been executed. The interpretation has allowed the drawing of the map of the top of the buried limestones presented in fig. 13, which shows the thicknesses of the Numidian Flysch which outcrops in a large part of the area (formation 5 in the geologic map of fig. 3). In order to show the general behaviour of the layers seven cross sections are presented in figg. 14 and 15, the traces of which are plotted in fig. 13. In the cross sections plastic and elastic formations are distinguished.

An approximative evaluation of the resonance effects can be obtained by the calculation of the predominant periods, using the following relation (Drakopoulos, 1978):

$$
T=4 H / V s,
$$

where $T$ is the resonance main period, $H$ is the thickness of the layer and $V s$ is the shear waves velocity. The values of $V s$ have been roughly calculated starting from the compressional waves velocities, assuming a Poisson coefficient of 0.3 , which is justified by the consideration that the main parts of the superficial layers are constitued by consolidated flysch or limestones. The assumption of a Poisson coefficient as high as 0.4 should raise the values of the predominant periods of about 30 per cent, without any large change in the frame of the predominant periods. The obtained map is presented in fig. 16.

\section{Conclusions}

The choice of $20 \mathrm{~km}$ and $100 \mathrm{~km}$ as examples of focal distances in order to calculate the conservative values of PGV risk, 
roughly reflects the actual mean distances of the normal and intermediate earthquakes in the area.

Nevertheless the map of " a priori " zoning gives only a rough sketch of the distribution of the seismic risk without any detail concerning the lithological differentiations in every geological formation.

The seismic and density surveys have allowed the drawing of the map of the increments of the macroseismic intensities, which gives a detailed sketch of the area; it is in fair accordance with the known geological and lithological characteristics. It should be noticed that the mapped values are only relative increments referring to hypothetical earthquakes.

The map of macroseismic intensity increments, however, does not take into account the resonance effects. The study of the thicknesses of the involved formations, even though carried out in a restricted area, has allowed the mapping of the spatial distribution of the predominant periods.

It should be noticed that in the case of large earthquakes most of the vibrations generally have periods too long to trigger resonance in the relatively thin shallow layers.

The soil responses of the actual situations, however, which in most cases are represented by a multilayered pattern, are more complicated than those of the single layer pattern.

In the studied area the seismic responses can be evaluated, in the light of the obtained results, by means of a reasonable integration of the data: the earthquake risk (PGV or PGA) can be suitably resettled using, instead of the general and world-wide parameters of the magnitude-soil-distance relations (Faccioli, 1977), the local data concerning focal distances, seismic rigidity properties and eventual resonance effects.

It should be taken into account also the risk connected with tsunamis originating in Southern Tyrrhenian sea (Caputo et al., 1974). 


\section{REFERENCES}

Caputo, M., Keilis-Borok, V. I., Kronrod, T. L., Molchan, G. M., Panza, G. F., Piva, A., Podgaetskaja, V. M. and PostPishl, D., 1974 - The estimation of seismic risk for Central Italy. "Ann. Geof.", 27, pp. 349-365.

Cosentino, P., 1978a - Seismicity and earthquake risk in Western Sicily, "Ann. Geof.", 31, pp. 243-260.

Cosentino, P., 1978b - Statistical processing of seismological data for earthquake engineering applications. "Proc. of 6th Eur. Conf. Earthq. Eng.", Dubrovnik, 1, pp. 39-46.

COSENTINo, P. and ENESCU, D., 1976 - Further statistical aspects of macroseismic activity in Sicily based on ten centuries data. "Riv. Ital. Geof. Scien. Aff.", 3-4, pp. 107-113.

Cosentino, P. and Ficarra, V., 1974 - I terremoti in Sicilia dall'anno 1000 al 1968: uno studio analitico e statistico. "Ann. Geof.", 3-4, pp. 517-537.

Cosentino, P. and Ficarra, V., 1975 - Catalogo dei terremoti più intensi avvenuti nell'area siciliana dall'anno 1000 al 1968. "Lav. 1st. Geof. Min. Univ. Palermo", 14 pp..

Cosentino, P. and Luzio, D., 1977 - Truncated exponential frequencymagnitude relation applied to the Sicilian earthquakes. "Publ. Inst. Geophys. Pol. Acad. Scienc.", A-5 (116), pp. 211-220.

Drakopoulos, J. C., 1978 - The importance of a complete microzonation procedure and reliability of the existing methods. Summary in "Boll. Geof. Teor. Appl.", 20, p. 214.

FACCIOLI, E., 1977 - Bases for a methodology of seismic microzoning. "Unesco Report", Mexico City, p. 138.

Medvedev, S. V., 1965 - Engineering seismology. "Israel Program for Scientific Translations", Jerusalem. 